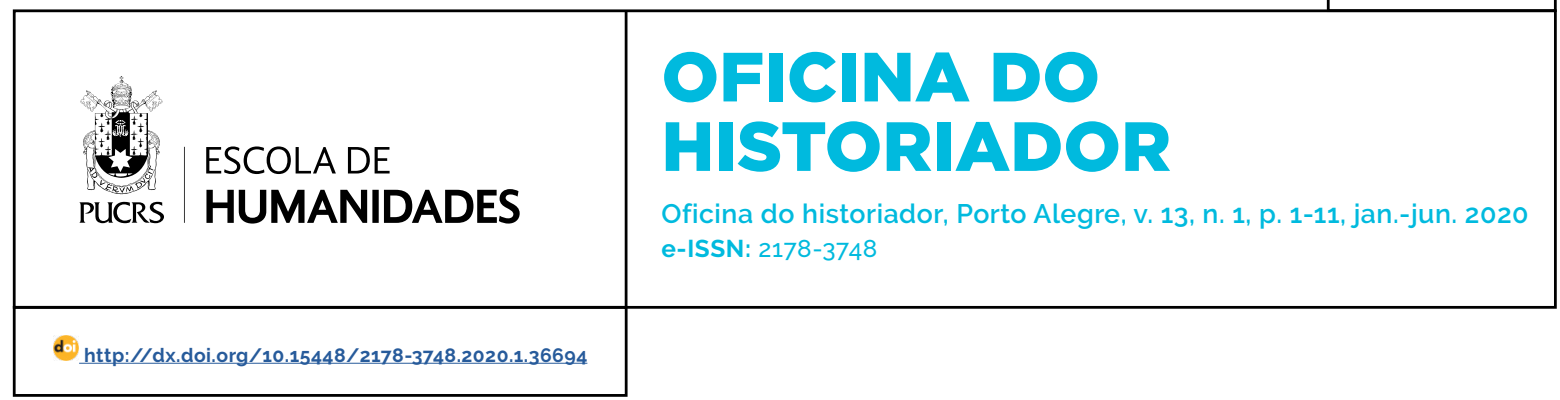

DOSSIÊ

\title{
Assembling a site of acquisition: knowledge production and drone survey at Dunbeg Fort
}

\author{
Assemblagem de um local de aquisição: produção do conhecimento e prospecção \\ com drone em Dunbeg Fort
}

Sterling Mackinnon ${ }^{1}$ orcid.org/0000-0003-3080-5363 sterling.mackinnoniii@kellogg. $\underline{\text { ox.ac.uk }}$

Recebido em: 20 dez. 2019. Aprovado em: 10 jan. 2020. Publicado em: 14 jun. 2020.
ABSTRACT: Geo-spatial visualising technologies are finding dynamic articulation within contemporary archaeology. With increasing regularity, archaeologists are using methods like drone-based photogrammetry to construct immersive spaces for research, analysis, and public-facing historical reconstructions. The rate at which they have been folded into the discipline, however, has outpaced efforts to critically theorise them. Too often these "new" forms of archaeological media are handled unreflexively. Often they are presented as easily knowable or self-evident. This paper attends to what it identifies as the contingencies inherent to the production of such media. Using theorists like Donna Haraway and Karen Barad. it specifically attends to notions of "partial objectivity", "situated knowledges" and "embodiment in contemporary archaeological practice. Centred around a series of observations conducted as part of an ethnography of the Discovery Programme's involvement in the Cherish Project (a collaborative EU-funded research initiative designed to monitor the impacts of climate change on coastal heritage sites in Ireland and Wales), it targets processes of data acquisition for photogrammetric modelling at the site of Dunbeg Fort in Co. Kerry, Ireland.

KEYWORDS: Photogrammetry. Embodiment. Knowledge Production.

RESUMO: As tecnologias geoespaciais de visualização tem encontrado uma articulação dinâmica com a arqueologia contemporânea. Com crescente regularidade. os arqueólogos têm usado métodos como a fotogrametria a partir de drones para construir espaços imersivos para pesquisas, análises e reconstruções históricas voltadas ao público. A velocidade a qual eles foram incluidos na disciplina, no entanto, ultrapassou os esforços para teoriza-los criticamente. Com demasiada frequência, essas "novas" formas de midia arqueológica são tratadas de maneira não-reflexiva. Muitas vezes, são apresentadas como facilmente reconheciveis ou mesmo evidentes. Este artigo atende ao que identifica como contingências inerentes à produção de tais mídias. Utilizando teóricos como Donna Haraway e Karen Barad, ele atente especificação a noções de "objetividade parcial", "conhecimentos situados" e "incorporação" na prática arqueológica contemporânea. Centrado em torno de uma série de observações conduzidas como parte de uma etnografia relativa ao envolvimento do Programa Discovery no Projeto Cherish (uma iniciativa de pesquisa colaborativa financiada pela EU, projetada para monitorar os impactos das mudanças climáticas em patrimônios costeiros na Irlanda e no País de Gales), tem como alvo os processos de aquisição de dados para modelagem fotogramétrica no sitio de Dunberg em Co. Kerry, Irlanda. PALAVRAS-CHAVE: Fotogrametria. Incorporação. Produção de Conhecimento. 


\section{INTRODUCTION}

It had been getting down to the wire. After four days of rainouts and windstorms we were finally going to be able to get the drone up and do some photogrammetry. In my capacity as the ardent and curious ethnographer-in-training, much of my experience in County Kerry up to this point had largely been defined by assuring my respondents that-irrespective of the foul weather-I was still getting valuable data. Today, however, was different. The mood around the breakfast table was lifted. Everyone compulsively checked weather and surf report applications to confirm what was evident from looking out the window; the conditions were finally right. Since arriving from Dublin, we had made several short visits to Dunbeg Fort in preparation for this very break. And so, after loading the car with all the necessary implements and kit, we set off to return again, feeling prepared and eager.

I was travelling with two field archaeologists and the senior geo-surveyor from the Discovery Programme, an Irish research institution centred on technology and innovation in archaeology. The Discovery Programme is also one of four core partners in the Cherish Project; an EU-funded research initiative designed to monitor the impacts of climate change on coastal heritage sites in Ireland and Wales through digital visualisation technologies. Dunbeg is one of these sites, almost a flagship of sorts. A remarkably well preserved and heretofore heavily touristed Iron Age promontory fort, Dunbeg had recently experienced dramatic erosion and collapse; so much so that it was closed to the public after ceding over 3,000 cubic metres of landscape to the sea during a storm event in the winter of 2017. It is this very volatility that makes it an ideal proof-of-concept test site, both for the Discovery Programme and the Cherish Project more broadly. Three years into the five allocated for the project and Dunbeg has been both surveyed and modelled more than any other within the Discovery Programme's remit. These models-which capture both the site's prominent dry-stone walling and the rapid encroachment of the eroding headland in vivid detail-function either as tools of illustration and public engagement or as the basis from which raster-based digital surface models can be derived and comparatively analysed.

One of the core deliverables for Cherish is the production of a baseline dataset comprised of digital visual media products ranging from highly accurate point clouds to hachure plans and thousands of "raw" digital images. In making digital visualisation-and 3D modelling in particularso central to its cause, the Cherish Project is emblematic of the "digital turn" being sustained within archaeology more generally. Whether it is in the construction of immersive spaces for collaborative research or public facing historical reconstruction, archaeologists-particularly in Europe-have embraced advancements in photogrammetry, laser scanning, and VR/AR with palpable enthusiasm (BENDICHO, 2013; FORTE, 2014; 2012; FORTE; PIETRONI, 2009; FORTE; KURILLOU, 2012; MORGAN, 2009; CORNS et al, 2017; CORNS; KENNEDY, 2015; CORNS; SHAW, 2009; DRAP et al, 2017). The discipline, however, is turning towards the digital with a concerning lack of critical reflexivity, particularly in its relationship to the digital visual media that it finds itself now capable of producing. Theoretical sectors of the discipline, certainly, have readily embraced poststructural, extra-lingual, and phenomenological discourse since the 1980s. From the advent of Ian Hodder's "post-processualism", to the work of scholars like Yanis Hamilakis, Chris Fowler, or Gavin Lucas, contemporary discourses on new materialism, assemblage theory, or relational realisms have found innovative articulations in archaeological circles (HODDER, 1982; HODDER, 1997; HAMILAKIS, 2017; HAMILAKIS; JONES, 2017; FOWLER, 2013; FOWLER; HARRIS, 2015; LUCAS, 2012). Yet the development of such concepts has been dogged by the persistent schism or gap between the theories proposed and their respective potential for methodological application. Often it is the case that such theoretical advances either cannot find convincing articulation or evidence within given datasets, or that a given theoretical framework is simply 
so broad and enveloping that it superficially can apply to all data (LUCAS, 2012). Furthermore, the majority of the literatures attempting to resolve these schisms have primarily focused on their application in traditional excavation contexts (FOWLER, 2013). As archaeology-in-practice becomes increasingly centred around methods of digital visualisation, however, new problems emerge. For one, archaeology has struggled to acknowledge the reflexivity inherent to the media it traditionally produces. Whether 2D, 3D, or otherwise, archaeologists too often produce and circulate media where "landscapes, lifeways, human and non-human entities are portrayed as static, timeless, uncomplicated or easily knowable" (PERRY, 2009; PERRY; BEALE, 2015). Research initiatives like the Cherish Project are designed to incorporate suites of technological resources and instruments that update and evolve rapidly. As such, our capacities to empirically understand both the methods pursued and media produced as either socially constructed-or partially subjective-are frequently outpaced by the rate at which new methods are adopted and employed. The practice of digital survey, monitoring, 3D modelling, or analysis, then, warrants further and consistent critical theorising.

On an earlier trip to Ireland, I had been given a crash course on the content the Discovery Programme had already generated for Cherish, including models of Dunbeg Fort both before and after its collapse. These demonstrations evidenced the clear efficacy this media has to perform a range of analytical tasks necessary to make functional recommendations about future monitoring concerns. However, given the conceit of the project-namely its attendance to cultural resources that will likely either be disappeared or seriously compromised in the not-to-distant future-it's entirely possible that much of this data/ media will be the only remaining record of some of these sites. As such, they are far more than just self-evident analytical tools. They are loaded with a distinct potential to produce nuanced material understandings of archaeological heritage in contexts that extend beyond engaging with a physical landscape. The question, then, becomes; what type of knowledges are these digital visual products capable of carrying? Or, perhaps more specifically, how are methods based in digital visualisation changing the production of archaeological knowledge?

Driving from our hotel to the site I found myself simultaneously attempting to both clear my head of expectation and sharpen the theoretical lenses I'd brought with me into the field. I had a rough idea of how the process ostensibly worked. And while I wanted to render myself as receptive as possible to the observation of the unexpected, I had also primed myself to watch for specific things. All the prescribed methodologies gathered within in the overarching Cherish Project workfow-from drone-based photogrammetry to laser-scanning or aerial photography-require the enactment of specific material engagements with landscapes, instruments and softwares. They are all also necessarily iterative and multi-sited by design; the data derived in these initial stages is ultimately commuted to desktops and various softwares for processing and visualisation at later stages. As such, the configuration and circumstances dictating both the protocol and enactment of on-site data acquisition will likewise hold considerable bearing and influence over the data as its translated across interfaces for visualisation and rendering. On the one hand, the relationship between the performed material enactments with instruments or landscapes in order produce either images or spatial coordinate data, say, is relatively evident. Furthermore, the relationship between such data and their application in analysis contexts is likewise often straightforward. I came to Dunbeg, however, hoping to tease out a slightly thornier relationship; namely that between the performed material engagements inherent to the acquisition of Cherish data and the knowledges such data could carry. As a result, I entered the field with particular concerns in mind; the types of embodiment produced through these procedures, for example, or how conditions necessary to conduct drone-based landscape surveys were predicated on the construction of contingent 
frameworks of reference. In attending specifically to the stages of acquisition observed at Dunbeg, what I will illustrate through the latter portions of this paper is how the dense interrelation of the components and interventions assembled in acquisition become co-constitutive of what such data can both do or mean as it coheres into tools for teaching, analysis, or reconstruction. Attending to the aspects of contingency present in the derivation of archaeological data is not necessarily novel. Doing so, however, is necessary in order to more meaningfully theorise the digital objects and media products such practices eventually come to comprise.

\section{"SITUATION AND ENTANGLEMENT"}

Scientific media is often used to derive, illustrate, or support knowledge claims. The difficulty, however, is that "it is all too easy to assume that scientific images show exactly 'the things themselves as they appear' without paying attention to the considerable work it takes for scientists to produce such pictures" (VERTISI, 2015. p. 8). As a consequence, any discussion of scientific media-particularly those used in empirical research-necessitates attending to both the contingencies inherent to their production and considering how these contingencies might elaborate the knowledge claims such images can produce. Scholars like Bruno Latour and Tim Ingold-via either the notions of Actor Network Theory or Meshworks their work has respectively developed-have alternately attended to the constructivist derivation of scientific knowledge in many contexts (LATOUR, 2009; INGOLD, 2011). Both, furthermore, have foregrounded either relationality or agency as key devices to advancing our understanding of material objects as more than simply inert things. The difficulty in squaring the work of either Latour or Ingold in our consideration of digital archaeological media, however, lies in the degree to which such theoretical frameworks might prevent us from identifying how relational and/or agential components of scientific practice endure and persist beyond discrete relational configurations and across processes of flux or translation (FOWLER; HARRIS, 2015). The iterative and multi-sited nature of photogrammetric modelling is predicated on a systematic process of translating and abstracting performances of measurement into various spatial contexts (from the field to the computational workspace, etc.). As such, in the project of addressing the contingency necessary to produce archaeological media, the question becomes both how the relational and situational circumstances of production are configured, and how such factors become inscribed in data that is first produced and iteratively reconfigured at later stages.

Writing in the late 1980's, Donna Haraway charged readers to reimagine our notions of empiricism in order to effectively account for "the radical historical contingency of all knowledge claims" and still produce "faithful accounts of a 'real' world" (HARAWAY, 1988, p. 579). For Haraway this requires reconfiguring how we understand the relationship between distance, location, mediation, embodiment, and objectivity. The "infinite vision" we might associate with satellite photography, for example, or the panoptic overviews afforded through the photogrammetric modelling of landscapes, are re-cast here as apparatuses of illusion. Not only do such images problematically provide no transparency about how they were made, but in so doing obscure the embodied perspectives embedded within them. In deliberately placing a premium on both positionality on location, however, we can approach an understanding of objectivity that accommodates difference and contingency through its attendance to conditions of partiality. Gathered under term of "situated knowledges", Haraway foregrounds circumstance and orientation in order to contend that "objectivity turns out to be about particular and specific embodiment", that "only partial perspective promises objective vision" (HARAWAY, 1988, p. 582-583).

Photogrammetry proves a particularly interesting test-case through which to consider Haraway's notion of partial objectivity. Long before the advent of structure from motion (IE, the most contemporary iteration of photogrammetry now 
widely used to generate 3D models), the Discovery Programme employed photogrammetric methods to aerial photography in order to generate georectified "ortho-images". Every photograph possesses a degree to radial distortion emanating from the focalisers within it. In the case of aerial photography, this distortion becomes particularly exacerbated at or around points of elevation. As such, overlapping images were pixel-matched in order to evenly distribute focus across a collection of photographs, eventually cohering into 2D images that could then be accurately geo-rectified to the pixel. As such, the empirical value of a geo-rectified photogrammetric image is produced through the systematic amalgamation of partial perspectives. Ironically, however, it is this very same process that effectively obscures the partiality inherent to the resulting product once reified as ortho-image.

Yet perspective, situation, or partiality, in this case, pertain to much more than the distribution of focus or distortion across a photograph. Any data, be it a photograph from a drone or a sparse point cloud from a laser scanner, is the result of a performed intervention between a given practitioner and the phenomena being observed. As such, another issue with the already established problem of assuming scientific images simply show "the things themselves as they appear" lies in the correspondence between representation/ abstraction and notions of realism it suggests. In an effort to "disentangle realism from its traditional representationalist formulation", Karen Barad has suggested that "images or representations are not snapshots or depictions of what awaits us but rather condensations or traces of multiple practices of engagement" (BARAD, 2007, p. 51, p.53). As a theoretical physicist, Barad (via the philosophy-physics of Neils Bohr) contends that even a simple abstracted concept like the position of a particle in motion:

...cannot be presumed to be a well- defined abstract concept; nor can it be presumed to be an individually determinate attribute of independently existing objects. Rather, position has meaning only when an apparatus with an appropriate set of fixed parts is used.
And furthermore, any measurement of position using this apparatus cannot be attributed to some abstract, independently existing object but rather is a property of the phenomenon-the inseparability of the object and the measuring agencies (BARAD, 2007, p. 139).

Barad, in so squarely foregrounding entanglement, dramatically reconfigures the perceived distance between an observer and the phenomena observed. Such a suggestion is also foundational to one of the more striking and instructive philosophical notions she develops. Deferring again to Bohr, Barad elaborates the notion of "complementarity" to construct a radical theory of knowledge production. As one of the central notions within Bohr's larger theory of quantum physics, the law of complementarity contends that any particle in motion cannot have simultaneously determinate values. The very act of measuring a hypothetical particle's position, then, means the same particle's momentum becomes necessarily unmeasurable. As a result, the material entanglement required to either perform scientific measurement or produce reliable descriptions of observed phenomena negates any supposed representational distance between the production of knowledge and the knowledge produced.

Bohr argues that scientific practices
must therefore be understood as in-
teractions among component parts of
nature and that our ability to understand
the world hinges on our taking account
of the fact that our knowledge-making
practices are social-material enact-
ments that contribute to, and are a part
of the, the phenomena we describe
(BARAD, 2007, p. 26).

If we accept that "we are part of the phenomena we describe", and that the content we produce through experiment are condensations of entangled and performed interventions, our relationship to empirical data necessarily changes. A GPS coordinate used to geo-rectify an orthoimage or a 3D landscape model, for example, is no longer understood to simply abstract the position of a precise geographic location. On the contrary, it's more accurate to understand this coordinate as 
a document of a specific phenomenon comprised of networks of reference, an enacted intervention, and the mediation of instruments and position. Making this shift enables us, as scientists or producers of knowledge, to more effectively accommodate the contingency inherent to our respective practices. Doing so doesn't invalidate or compromise the empirical value of knowledges produced. On the contrary, it only makes it richer.

\section{"DIGITAL EMBODIMENT"}

Given the centrality of digital visualising technologies to the work observed at Dunbeg Fort, however, the theoretical application of Haraway or Barad sought here requires attending specifically to questions of embodiment. All too frequently imaginations of the digital are bound up in notions of the disembodied. To a problematic extent, the entrenched legacy of both post-cartesian rationalism and the assumed binary divide of the real/virtual has long loomed over the discourse of both the digital and computation (MUNSTER, 2006; HAYLES, 1999). Yet much as Natasha Myers has described protein crystallographers melding with the tools of their practice to comprise "human computerlenses" in Rendering Life Molecular (2015)-or as Janet Vertisi has described planetary geologists learning to project both their faculties of vision and movement to Martian landscapes in Seeing Like A Rover (2015)-movement, sensation, and material interchange find profound articulations in the digital experience. Whether in the haptic navigation of a VR environments, or the projected vision enabled through something like an electron microscope, conditions of embodiment are both variably distributed and re/produced across digital interfaces and digital methodologies. Specifically as it pertains to the issues of scientific representation outlined by both Haraway and Barad, this mediated dispersal of embodiment further elaborates how we evaluate and consider the knowledges and truth claims produced through such methods. Images generated through "human computer lenses", then, go far beyond mimesis; they're densely mediated and co-produced, and the conditions or arrangement of this co-production likewise determine the partial nature of the objectivity they carry.

Much of this is bound up in the degree to which the data Cherish produces is not simply "acquired". Both of the core datasets necessary to produce 3D models (IE, both the photography and the spatial framework of locative coordinates necessary to register the resulting images in coordinate-based space) are produced through the way sites of acquisition are assembled. The dense interrelation of the targeted landscapes, the instruments used to perform acquisition, and the expertise of practitioners produce distinct spatial configurations that both dictate and enable specific ways of moving across and viewing archaeological sites and heritage landscapes. The ways of seeing and choreography of movement produced through these arrangements, then, likewise determine the "partial objectivities" inscribed into the data produced. Given how photogrammetry functions as a means to aggregate discrete photographic and locative datasets into cohesive 3D visualisations, the knowledges carried by such models are derived from the configuration and distribution of enacted perspectives and performed movements. The issue, however, is that as these models cohere into discrete digital objects, such factors are absent in their reified forms.

In its rendering of threatened archaeological landscapes, the Cherish Project protocol for photogrammetric modelling roughly mandates the following:

1. After a preliminary site assessment, a series of control targets-clearly visible from the air-are distributed across the area of interest.

2. These targets are then registered within a given geographic coordinate system using either an on-site Real Time Kinetic network or a virtual base-station (both configured to available satellite networks).

3. A series of automated overhead drone-based photographs programmed using the DJ Groundstation application. 
4. A series of oblique drone-based photographs, taken manually.

5. All the locative and photographic data is then commuted over to Agitsoft Metashape, a modelling software where the entire collection of photographsafter the geo-referenced control targets have been located and populated across the image cache-are processed into sparse point clouds, dense point clouds, meshes, and textures.

Each of these respective stages necessitate particular types of material engagement with interfaces, instruments, media, and landscape, the likes of which then become co-constitutive of both the accuracy and cohesion of the resulting models. Given both the established relationship between situational contingency and the empirical products generated through scientific experiment as well as the multi-sited process through which Cherish practitioners ultimately subject their data, questions abound as to how these condensed traces of material engagement change and cohere as they move through iterative stages of production. Rather than follow the process through its respective stages of post-production and visualisation, however, I will limit my observation of Cherish modelling protocol to the primary stages of acquisition; highlighting how a physical heritage landscape is initially translated into a digital, or virtual context. The reason for this is mostly practical; this paper is derived from a PhD in progress which aims to address these questions in of wider contexts. Yet the degree to which the initial acquisition of data dictates the empirical content of a given model as it evolves cannot be overstated. These initial traces-irrespective of being re-topologised, decimated, or condensed at later stages-are propagated throughout each stage of the modelling process. As such, they are also intrinsically bound up in the knowledges processed models carry and, by extension, indicative of how they can be interpreted and used in the future.

\section{DISTRIBUTING "CONTROL"}

Arriving at Dunbeg Fort, we began the process by consulting a pair of maps to determine the general boundaries of our survey. Before leaving the hotel that morning, Rob-the Discovery Programme's senior geo-surveyor-had used the drone-flight application "DJI Groundstation" to configure the flight path for the automated series of orthophotos we would initiate later. This programmed flight path comprised a virtual bounding box over an image of the promontory taken from google maps. We contrasted this map with a still image of a Dunbeg model that had been generated from a previous survey in the autumn of 2018. Toggling between these two images, we began planning where best to register the coordinate readings that would later be used to geo-rectify the model in the stages of processing and visualisation. There was a very real way in which the registration of control targets, and the coordinates associated with them, felt just as important the photographs we would later capture.

One of the primary objectives for this entire trip, in fact, was to acquire coordinate information necessary to retrofit previously unregistered models of the same landscape. Part of what these initial efforts evidenced, too, was the degree to which our approach and execution would conform to a concept of the model Rob had imagined ahead of our arrival. The plan and placement of our targets, he would explain, would be comprised of six initial targets, the arrangement of which would best ensure an even distribution of registered coordinate data at later stages in the modelling process. Two more targets would be deployed randomly within the boundary he had conceived and would function as "confidence checks" in later stages (IE, the respective error or accuracy associated with these control points would assist in confirming the error or accuracy associated with the control points defining the boundaries of the resulting model). Once we had arrived at a consensus about where and how we should move about the site, we set off.

The site itself-or perhaps, more precisely, the boundaries of the survey we had planned- 
includes the archaeological structure, the cliff on which it was built, and the two adjoining field enclosures directly above it. Compassing nearly 30,000 square metres, the entire landscape tilts gently southward to the sea, making it difficult to physically see the main Iron Age structure from anywhere but within its immediate proximity. As such, as Rob and I roamed the area deploying and registering each target, we would frequently refer to one of the two maps we had brought in tow to ensure we were where we had planned. The targets themselves were thick plastics placards emblazoned with a black and white checkered pattern and codes specific to each individual target. Each target was staked to the ground, after which we would use a Trimble GPS antenna to register the precise location for the centre of each target. The coordinate readings-while recorded onto the SD card in the antenna using the naming convention "topo point 1...n"-were also documented in a field notebook. Finally, after each reading, a digital photograph was taken of the target and its respective orientation to identifiable features in the landscape. All of this data-the codes on the targets, the corresponding GPS coordinates, the photos of each target's orientation, etc.-were then bundled together to ensure that the correct readings could be matched with the correct targets within the photographs during processing.

Once the 8 initial targets had been staked and registered, we again deferred to our maps to locate stable and permanent features around the landscape that could identified across any

model of Dunbeg, regardless of when the photographic data had been acquired. After identifying a series of large stones and fence posts, we began another trip around the site to register coordinate data for these features as well. Given that this data that would be used to retrofit and geo-rectify earlier models, they were recorded onto the antenna's SD card using the naming convention "retro $1 . . . n$ ".

This distribution and registration of control targets across Dunbeg not only evidences a planned and performed engagement with both landscape and tools of measurement but, given how such processes are centred around locative data, they become particularly interesting to consider within the frameworks of Barad or Haraway. The accuracy, and therefore value, of each coordinate-based control point is densely bound up in its relationship both to the landscape and the network of other control points to which it relates. Regardless of either the precision of these tools of measurement, or the sophistication of the softwares that will later collate them, the relative accuracy of the resulting models directly corresponds to the configuration and arrangement of these original points of reference. As a consequence, then, the empirical content of this network is not only contingent on degree to which it might viewed as partially objective, but the construction of this network is also produced through a sequence of performed interventions or measurements that cohere into something stable and abstracted. Perhaps most significantly, however, is the way in which the acquisition of all other data at Dunbeg is predicated on the derivation of this locative positional network. Much like the system of "circulating reference" Bruno Latour described in his now famous ethnography of soil scientists in the Amazon, the distribution of control points at Dunbeg produces the conditions through which the visual content that ultimately composes the model can used for analysis and knowledge claims (Latour,1999). Ultimately, then, we can view this initial bundled cache of data in two ways; as an abstracted spatial network of a physical landscape and as a document of performed measurement and movement across such landscapes. Particularly in the capacity which this bundled data cache is ultimately used to render digital images and their cohesion as point clouds or $3 \mathrm{D}$ models accurate, this record of performed measurements points to how the resulting media and visual products are inherently more-than-mimetic. Crucially, however, is also the degree to which the inscription of the "partial objectivities" produced through the registration of control targets endures throughout the subsequent processes that follow. 


\section{PHOTOGRAPHY}

Given the contours of Dunbeg's landscape, which is both steep and dramatic, two types of photographs are necessary to produce a $3 D$ model; orthogonal overheads and obliques. This second phase of acquisition begins with the overhead photography. Using the aforementioned "DJI Groundstation" app, Rob has pre-configured an automated flight path for the drone (a DJI Phantom IV Pro+). The metrics for this initial round of photography, IE flying altitude, pixel resolution, time of flight, and number of photographs, are not only pre-determined but are all also variably interrelated. Adjust the number of photos to be taken in flight, for example, and the time of flight correspondingly changes. Adjust the prescribed altitude and the resolution likewise changes. For this initial round at Dunbeg the programmed flight produced the following statistics:

\section{Altitude: 6om}

Resolution: $1.6 \mathrm{~cm} / \mathrm{px}$

Flight Time: 13 Minutes

Total Photos: 260 images

Like the "human-computer lenses" of Myers' protein crystallography labs, part of what becomes evident in attending to these metrics is how this initial round of photography is inherently coproduced. Rob initiates none of these individual photographs himself but configures the process by which they'll be acquired. Similarly, while not physically travelling with the camera as it operates, the drone executes its flight path in accordance with Rob's design. In terms of embodiment, then, the faculties of vision and movement necessary to acquire photographic data at this scale are distributed across the assembled instruments and interfaces. Rob sees what the drone sees, almost as if he were hovering 6om above the promontory himself.

In contrast to the orthogonal passes, the enactment of oblique image capture produced a distinctly different dispersal of vision across the assembled apparatus of acquisition. In simultaneously piloting the drone and shooting the photography, Rob's eyes remained locked on both the screen and controls throughout each pass. Remarkably, in fact, he barely looked at the drone as it was in flight at all. Between the screen of the tablet and the camera mounted to the drone, an interchange between lenses and interfaces enabled Robert to see through the apparatus. This was further compounded by the degree to which the performed shifting between vantages might be understood as a process seeking out or searching for the necessary perspectives. As such, the conditions of distance or partial perspective bound up in this articulation both corporeal sight and movement here acquired something of an inverse relationship to the articulation of the same conditions in orthogonal photography. In the case of the latter, the automated regulation of distance, movement, and vision were necessary in order to acquire a specific dataset. In the former, however, the apparatus-assisted mediation of both vision and movement worked to effectively close the distance physically separating Robert from his subject of inquiry. Crucially, however, because it is the cohesion of these datasets that ultimately resolves in exhaustive and accurate 3D models, the respective value of the resulting models is also predicated upon the systematic fitting together of partial or mediated perspectives.

Because both vision and position are mediated and configured in accordance with these apparatuses, they are also necessarily partial. The objectivity they afford, then, should be framed with these conditions of partiality firmly in mind. As a consequence, the resulting photographs (the likes of which will ultimately be geo-rectified stitched together as a three-dimensional point cloud) are much more than a self-evident representation of features on a landscape; they are a condensation of intervening measurements, performed movements, and dispersed vision inherent to this process.

\section{CONCLUSION}

The Discovery Programme has posted a small selection of Cherish-based models on their Sketchfab profile (a browser-based visualisation 
platform similar to YouTube, but for 3D modellers). These models are low resolution by default, and primarily function as tools of outreach or illustration. Little if any meaningful analysis could be performed on them. Floating on tiles, like minerals in a museum of natural history, they almost look like they were cut from a much larger, but unseen, digital landscape with scissors. The viewer can grab these models with their cursors, spin them around, or zoom in until their screen fills with nothing but blurry pixels. Four of the nine models the Discovery Programme has posted are of Dunbeg Fort; two are textured with photographs and two are visualised using ambient occlusion (a method that emphasises structure and shape and resembles pewter casting). They are all products of structure from motion-based photogrammetry derived from surveys performed in both June 2017 and April 2018.

Given the starkness of their digital framing and the crispness and detail of their appearance, they register-almost immediately-as the result of a clean, precise, and self-evident scientific practice. Nowhere visible are the control targets, GPS antennas, drones, or practitioners who produce them. Nowhere can the user sense the performance of intervention and motion that made this rendering possible. This is not to say that these visualisations should have to make their means of production readily visible within the model. It should be noted, too, that this is just one of the many ways of the Discovery Programme can visualise or use this data. Yet in attending specifically to their means of production, as we have begun to do in this paper, what we can see within, learn, or derive from these models changes. In attending to the specific conditions of material enactment and dispersed embodiment inherent to them, the knowledges such models are capable of producing or carrying become more complex through this acknowledgement of their contingency. They cease to appear as unproblematic snapshots and reveal themselves as dynamic condensations of a scientific performance. Furthermore, as digital objects that will be perpetually re-visualised and re- produced as they move across interfaces and platforms for any number of known or yet-to-bedetermined reasons, it is vital to remember that these conditions of partial objectivity, situation, or embodiment remain inscribed into the data as it travels and changes. As such, given their unique propensity to produce further knowledge claimseither through analysis or illustration-these factors will ultimately comprise new generative configurations in new contexts; crucially shaping how we might come to know or understand threatened heritage spaces like Dunbeg Fort.

\section{REFERENCES}

BARAD, K. M. Meeting the Universe Halfway: Quantum Physics and the Entanglement of Matter and Meaning. London: Duke University Press, 2007. https:// doi.org/10.1215/9780822388128.

BENDICHO, V. M. L.-M. International Guidelines for Virtual Archaeology: The Seville Principles. In: BENDICHO, V. M. L.-M. Good Practice in Archaeological Diagnostics, Natural Science in Archaeology. Cambridge: Cambridge Univ. Press; London: Springer, 2013. p. 269-283. https://doi.org/10.1007/978-3-31901784-6_16.

CORNS, A.; DEVLIN, G.; DEEVY, A.; SHAW, R.; SHINE, L. 3D-ICONS Ireland - Fulfilling the potential of a rich 3D resource. Internet Archaeology, v. 43, n. 2, p. 1-7. 2017. https://doi.org/10.11141/ia.43.12.

CORNS, A.; KENNEDY, L. Irish Archaeological Data: Toward a Framework. New Review of Information Networking, London, v. 20, n. 1-2, p. 66-72, July. 2015.

CORNS, A.; SHAW, R. High resolution 3-dimensional documentation of archaeological monuments \& landscapes using airborne LiDAR. Journal of Cultural Heritage, Amsterdam, v. 10, e72-e77, 2009. Suppl. 1. https://doi.org/10.1016/j.culher.2009.09.003.

DRAP, P.; PAPINI, O.; PRUNO, E.; NUCCIOTTI, M.; VANNINI, G. Surveying Medieval Archaeology: A new form for Harris Paradigm linking photogrammetry and temporal relations. Exploitation, Disciplinary Change. ISPRS-Archives, XLII-2/W3, p. 267-274, 2017. https://doi.org/10.5194/isprs-archives-xlii-2-w3-267-2017.

FORTE, M. Cyber-Archaeology: Notes on the simulation of the past. Virtual Archaeology Review, Valencia, v. 2, n. 4 p. 7-18, 2011

FORTE, M.; DELL'UNTO; N., ISSAVI, J.; ONSUREZ, L.; LERCARI, N. 3D Archaeology at Çatalhöyük. International Journal of Heritage in the Digital Era 1. Thousand Oaks, p. 351-378, 2012. https://doi. org/10.1260/2047-4970.1.3.351. 
FORTE, M.; PIETRONI, E. 3D Collaborative Environments in Archaeology: Experiencing the Reconstruction of the Past. International Journal of Architectural Computing, Thousand Oaks, v. 7. n. 1, p. 57-76, Jan. 2009. https://doi.org/10.1260/147807709788549349.

FOWLER, C. The Emergent Past: a relational realist archaeology of early bronze age mortuary practices. Oxford: Oxford University Press, 2013. https://doi. org/10.1093/acprof:osobl/9780199656370.001.0001.

FOWLER, C.; HARRIS, O. J. Enduring relations: Exploring a paradox of new materialism. Journal of Material Culture, Thousand Oaks, v. 20, 127-148, 2015 https://doi.org/10.1177/1359183515577176.

HAMILAKIS, Y. Sensorial Assemblages: Affect, Memory and Temporality in Assemblage Thinking. Cambridge Archaeological Journal, Cambridge, v. 27. n. 1, p. 169-182, 2017. https://doi.org/10.1017/ s0959774316000676.

HAMILAKIS, Y., JONES, A.M., 2017. Archaeology and Assemblage. Cambridge Archaeological Journal, Cambridge v. 27, 77-84. https://doi.org/10.1017/ s0959774316000688.

HARAWAY, D. Situated Knowledges: The Science Question in Feminism and the Privilege of Partial Perspective. Feminist Studies, College Park, MD, v. 14. p. 575-599, 1988. https://doi.org/10.2307/3178066.

HAYLES, K. How we became posthuman: virtual bodies in cybernetics, literature, and informatics. London: University of Chicago Press, 1999. https:// doi.org/10.7208/chicago/9780226321394.001.0001.

HODDER, I. (ed.). Symbolic and structural archaeology, New directions in archaeology. [S. l: s. n.], 1982.

HODDER, I., "Always momentary, fluid and flexible": towards a reflexive excavation. Antiquity, Cambridge, v. 71, n. 273, p. 691-700, Sept. 1997.

INGOLD, T. Being alive: essays on movement, knowledge and description. London: Routledge, 2011.

LATOUR, B. Pandora's hope: essays on the reality of science studies. Cambridge, Mass: Harvard University Press, 1999.

LUCAS, G. Understanding the archaeological record. Cambridge: Cambridge University Press methodology. Antiquity, Cambridge, v. 71, p. 691-700, 2012.

MORGAN, C. L. (Re) Building Çatalhöyük: Changing virtual reality in archaeology. Archaeologies, [S. L.], v. 5. p. 468-487, 2009. https://doi.org/10.1007/s11759009-9113-0.

MUNSTER, A. Materializing New Media: Embodiment in Information Aesthetics. Aldershot: Dartmouth College Press, 2006.

MYERS, N. Rendering life molecular: models, modelers, and excitable matter, Experimental futures. Durham, NC: Duke University Press, 2015. https://doi. org/10.3138/anth.59.2.ebro1.
PERRY S.; BEALE N. The Social Web and Archaeology's Restructuring: Impact. Open Archaeology, Berlin, V. 1, n. 1, p. 153-165, 2015.

PERRY, S. Fractured Media: Challenging the Dimensions of Archaeology's Typical Visual Modes of Engagement. Archaeologies, [S. l.], v. 5. p. 389-415, Sept. 2009. https://doi.org/10.1007/s11759-009-9114-Z.

VERTESI, J. Seeing Like a Rover: how robots, teams, and images craft knowledge of Mars. Chicago: The University of Chicago Press, 2015. https://doi. org/10.7208/chicago/9780226156019.001.0001.

Mailing address:

Sterling Mackinnon

Oxford OX1 2JD, University Offices,

Wellington Square, England, United Kingdom.

Zip code: OX1 2JD

\section{Sterling Mackinnon}

Dhil Candidate, School of Geography and the Environment - University of Oxford 